\title{
Investigating an API X65 steel pipe cladded with alloy 625
}

\author{
Rangel Knerek ${ }^{1}$ \\ Guilherme Vieira Braga Lemos ${ }^{2}$ (루 \\ George Vander Voort ${ }^{3}$ \\ Diego Aires de Freitas ${ }^{2}$ \\ William Haupt ${ }^{4}$ \\ Renan Landell ${ }^{2}$ \\ Diogo Buzzatti ${ }^{2}$
}

\begin{abstract}
Pipes (rigid risers and flowlines) are employed to transport oil and gas from the wells to the platforms. In these pipes, the fluids can be very corrosive and, therefore, corrosion-resistant alloys (CRA) must be chosen. Alloy 625 is a well-known CRA with improved corrosion resistance. However, nickel-based alloys have high cost compared to that of the low alloy steels, thus pipes entirely made of CRA are economically unfeasible. Internal coating with a thin CRA layer is a less expensive and suitable alternative than the solid CRA. An internal coating by overlay manufacturing process can induce phase transformations at the interface. In this work, an alloy 625 cladding layer was deposited in an API X65 steel substrate with an automatic weld overlay system using gas tungsten arc welding (GTAW) process (often referred to as tungsten inert gas (TIG) hotwire). Thus, this study aims at evaluating an API X65 steel pipe cladded with alloy 625. The results show a suitable nickel-based alloy overlay deposited in an API X65 carbon steel substrate.
\end{abstract}

Keywords: Welding; Clad pipes; GTAW; TIG hotwire; API X65 steel; Alloy 625.

\section{Introduction}

High strength low alloy (HSLA) steels are used in gas and oil transportation due to their improved mechanical properties, allowing pipes to work with elevated pressure, ensuring high productivity operations. However, in harsh environments, larger volumes of corrosive fluids containing $\mathrm{CO}_{2}$ and $\mathrm{H}_{2} \mathrm{~S}$ need to be transported through pipes, and this demand can be met by using corrosion-resistant alloys (CRA) [1,2]. Therefore, clad pipes were developed, where HSLA steels and CRA are combined to produce pipes with good mechanical and corrosion properties at a lower cost if compared to the solid CRA pipes [3]. Clad pipes consist of an outer carbon steel pipe with an inner CRA, where the steel pipe provides strength and toughness, while the CRA layer affords corrosion resistance [4]. Moreover, alloy 625 is a nickel-based CRA, with good weldability, improved mechanical and corrosion properties [5-7].

Clad pipes have been available for over 50 years. The rigid pipes can be manufactured by hot roll-bonding, explosive bonding, and weld overlaying. Weld overlay is a fusion-based welding process for depositing coats, allowing manufacturing clad pipes with various thicknesses, diameters, and lengths [8]. Besides, weld overlay is employed to seal the liner at the pipe ends and joint preparation of lined pipes $[9,10]$. TIG hotwire is often used for cladding critical parts of subsea equipment because it presents high efficiency, low heat input, and high quality [11-13]. Controlling the chemical composition of the coating layer of HSLA steels with Inconel 625 is required to avoid brittle phases. DNVGL-ST-F101 standard [14] requires the maximum iron content of $10 \%$ in the weld overlay. For API 6 A standard, the overlay iron content shall meet one of the following classes: Fe 5 and $\mathrm{Fe} 10$, which requires a maximum of 5\% and $10 \%$ content, respectively [15]. A welding process with low dilution should be used to meet these requirements. Therefore, the wire (in TIG hotwire) is heated by the Joule effect, which increases the deposition rate and consequently decreases the iron content on the alloy 625 cladding layer.

Song et al. [16] studied the influence of welding current at the alloy 625/X65 cladding interface of bead-on-plate welds. The niobium-rich MC carbide and Laves phase were mainly found in the columnar dendrite region. Niobium-rich MC carbide was noted for low peak current $(170 \mathrm{~A})$ and the Laves phase was observed for high current $(250 \mathrm{~A})$. The microstructures of the cladding layer were planar crystal, cellular crystal, dendrite

${ }^{1}$ Universidade Regional Integrada - URI, Campus Erechim, RS, Brasil.

${ }^{2}$ Laboratório de Metalurgia Física - LAMEF, Programa de Pós-graduação em Engenharia de Minas, Metalúrgica e de Materiais - PPGE3M, Universidade Federal do Rio Grande do Sul-UFRGS, Porto Alegre, RS, Brasil.

${ }^{3}$ Vander Voort Consulting LLC, Wadsworth, IL, USA.

${ }^{4}$ Universidade de Passo Fundo - UPF, Passo Fundo, RS, Brasil.

*Corresponding author: guilherme.lemos@ufrgs.br 
crystal, and equiaxed crystal from the interface with the base metal to the top of the bead. Moreover, the thickness of the planar crystal region and the dendrite crystal size increased with an improvement in the welding peak current.

Rajkumar et al. [17] investigated the mechanical properties of alloy 625 overlay on AISI 347 pipes produced by the GMAW-hardfacing process. Tensile tests of alloy 625 showed yield strength (YS) of $273 \mathrm{MPa}$ and ultimate tensile strength (UTS) of $690 \mathrm{MPa}$. Chong et al. [18] studied the mechanical properties at different temperatures $(24,100$, and $180^{\circ} \mathrm{C}$ ) of an API X65 steel pipe cladded with Incoloy $825 \AA$ by the GMAW process. At $24^{\circ} \mathrm{C}$, the base material (API X65) presented YS of $524 \mathrm{MPa}$ and UTS of $573 \mathrm{MPa}$. Elango and Balaguru [19] studied the mechanical properties of alloy 625 overlay on carbon steel by the GMAW process. The overlay top reached $215 \mathrm{HV}$, while the overlay surface (mid-cross-section) achieved $210 \mathrm{HV}$.

Lessa et al. [20] presented friction stir welding (FSW) to an API X65 steel cladded with alloy 625. In their study, Laves and $\mathrm{Nb}$ rich $\mathrm{MC}$ carbides were found in the cladding layer. Thus, the segregation of $\mathrm{Nb}$ and Mo elements into the interdendritic region occurred during solidification.

The current work aims at evaluating an API X65 steel pipe cladded with alloy $625 \AA$. Thus, mechanical properties were evaluated by microhardness and tensile testing. Furthermore, the microstructure of the materials (steel and nickel-based alloy) was analyzed.

\section{Materials and methods}

An API 5L X65 steel pipe with $114 \mathrm{~mm}$ external diameter and $8 \mathrm{~mm}$ thickness was the base material (substrate) in this work, a carbon steel for rigid pipes of the offshore industry [21]. Then, the ERNiCrMo-3 (alloy 625) was the filler metal for cladding. This consumable filler is equivalent to Inconel $625 \AA$, a nickel-based alloy for harsh corrosion fields. The chemical composition of the API X65 steel (obtained by optical emission spectrometer) and the ERNiCrMo-3 alloy (data from the supplier) are given in Table 1.

An alloy 625 layer (3.0 mm thickness) was deposited by a TIG hotwire overlay system, with an ERNiCrMo-3 wire (1.14 mm gauge). The shielding gas was argon (Ar) 99.998\%, with a flow rate of $12 \mathrm{~L} / \mathrm{min}$. To avoid pipe overheating during overlay, pulsed TIG was employed. The process conditions were: peak current of $180 \mathrm{~A}$; base current of $100 \mathrm{~A}$; peak and base current time of $0.1 \mathrm{~s}$; average voltage of $11.4 \mathrm{~V}$; hotwire current of $50 \mathrm{~A}$; wire feed rate of $1.0 \mathrm{~m}$. $\mathrm{min}^{-1}$; welding speed of $1.5 \mathrm{~mm} . \mathrm{s}^{-1}$; weaving amplitude of $5 \mathrm{~mm}$; and weaving frequency of $0.5 \mathrm{~Hz}$. Figure 1 shows the clad pipe.

The dilution was calculated via Equation 1, where: $\mathrm{D}(\%)$ is the dilution, $\mathrm{A}_{\mathrm{M}}$ and $\mathrm{A}_{\mathrm{R}}$ are the areas of molten substrate and weld reinforcement, respectively. Figure 2 illustrates the areas $A_{M}$ and $A_{R}$ on the cross-section of a

Table 1. Chemical composition of the materials (mass \%)

\begin{tabular}{lllllllllllll}
\hline \multicolumn{1}{c}{ Material } & C & Mn & Si & P & Al & Nb & Cu & Cr & Ni & V & Ti & Fe \\
\hline API X65 & 0.013 & 1.3 & 0.3 & 0.004 & 0.02 & 0.001 & 0.19 & 0.11 & 0.07 & 0.06 & 0.003 & Bal. \\
ERNiCrMo-3 & 0.012 & 0.02 & 0.14 & 0.007 & 0.17 & 3.55 & 0.02 & 21.5 & 65.2 & 8.7 & 0.21 & 0.41 \\
\hline
\end{tabular}
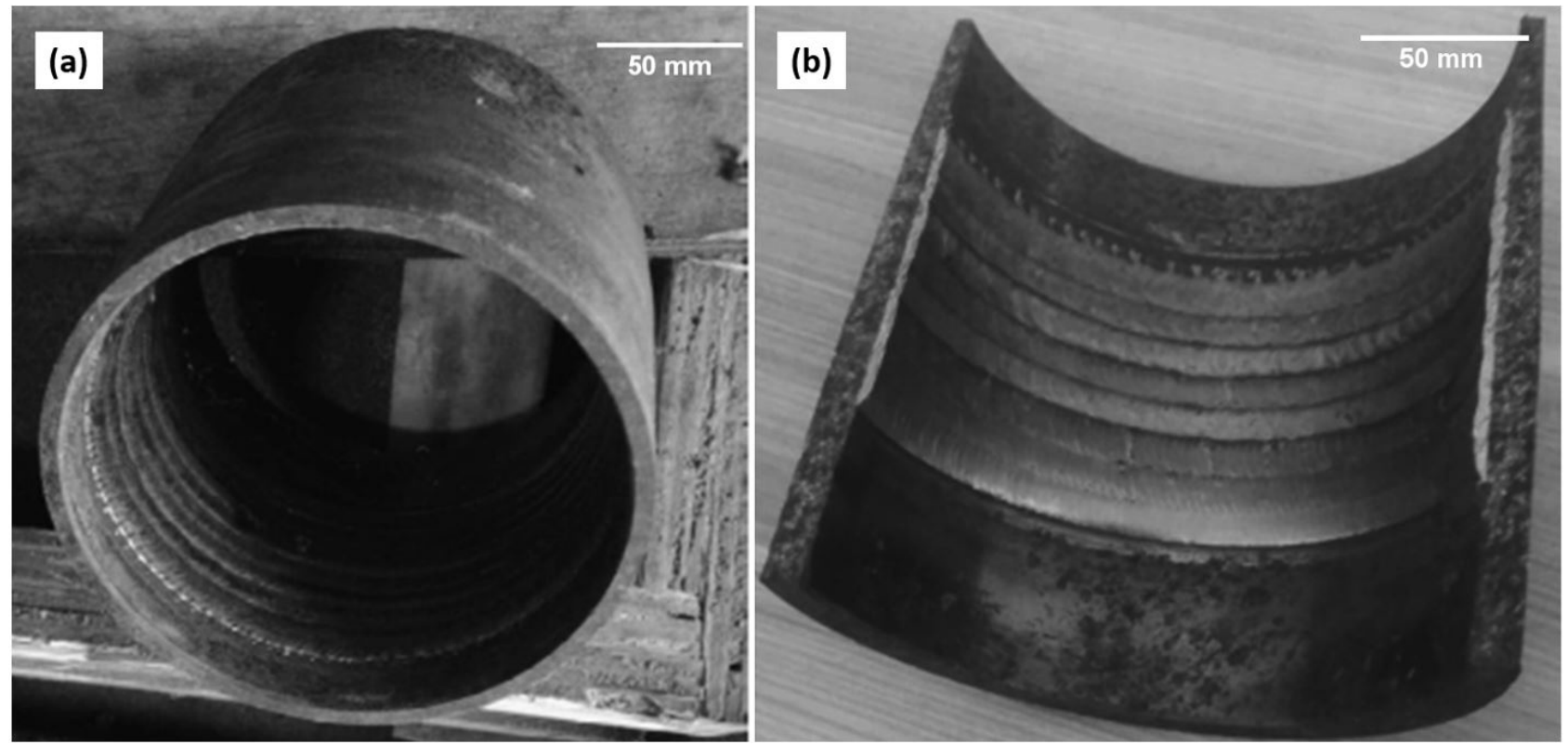

Figure 1. Clad pipe: (a) before cutting (b) cross-section. 
weld bead [22]. The areas $A_{M}$ and $A_{R}$ were measured via Image J software.

$$
\mathrm{D}(\%)=\frac{\mathrm{A}_{\mathrm{M}}}{\mathrm{A}_{\mathrm{M}}+\mathrm{A}_{\mathrm{R}}} 100
$$

Three tensile tests (ASTM E8M standard [23]) were performed to evaluate the mechanical properties of the API 5L X65 steel substrate (without cladding layer). Due to the available steel wall thickness, subsize specimens were extracted from the longitudinal direction of the pipe. Figure $3 \mathrm{a}$ shows the subsize dimensions. Furthermore, microtensile tests were carried out to investigate the local properties of the APIX65 steel and alloy 625 cladding layer. For evaluating the base metal and the weld metal, each two micro-sized specimens were machined by electric discharge machining (EDM), with dimensions shown in Figure $3 \mathrm{~b}$. Figure $4 \mathrm{~b}$ further displays the location of the micro-sized specimens.

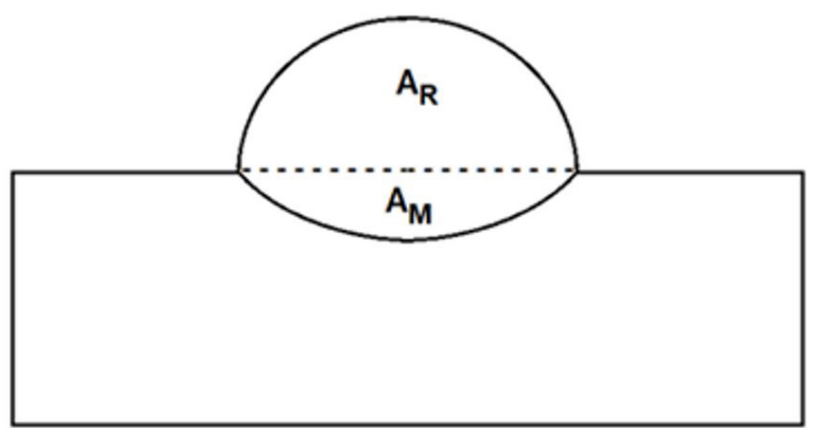

Figure 2. Weld bead geometry characteristics.
Microhardness measurements were used to evaluate local mechanical properties of the substrate (API X65 steel) and the cladding overlay (alloy 625).

Optical microscopy (OM) was firstly used to verify the microstructural features, with color etching $(37.5 \%$ phosphoric acid in ethanol, used electrolytically, at $6 \mathrm{~V}$ for 75 seconds). These images were taken using Nomarski DIC (differential interference contrast) illumination. Next, for an SEM investigation in a Tescan Vega $3 \mathrm{LM}$, the microstructure was revealed by $10 \%$ oxalic acid (electrolytically) at $6 \mathrm{~V}$ for 10 seconds.

Bending tests were done with an adaptation of the DNVGL-ST-F101:2017 standard [14], which specifies rectangular specimens extracted perpendicularly to the clad direction, to evaluate the overlay quality. Thus, bending samples shall be bent laterally up to $180^{\circ}$ without cracks or defects. Afterward, the samples were assessed by dye penetrant testing.

Finally, Figure 4 illustrates the locations for microhardness measurements, microsize tensile tests, and bending tests.

\section{Results and discussion}

\subsection{Mechanical properties}

Figure 5 presents the mechanical properties of the API X65 steel pipe cladded with alloy 625 . Therefore, subsize (SS) samples were selected to classify the X65 steel substrate in PLS1 or PSL 2 grade. As an average, the API X65 SS samples reached YS and UTS of 529 and $575 \mathrm{MPa}$, respectively. Thus, this steel can be classified as an API X65 PSL2 [24] (based on its chemical composition and tensile tests).

\section{(a)}

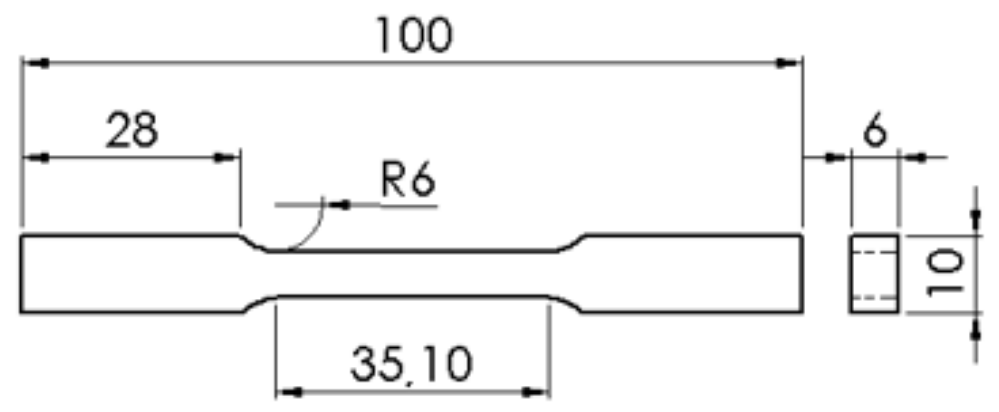

(b)

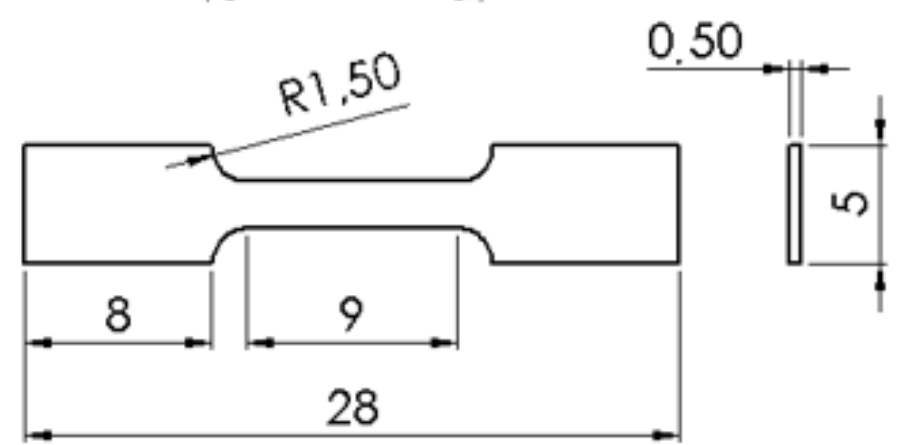

Figure 3. Tensile testing samples dimensions (in mm): (a) subsize (SS), (b) microsize (MS). 


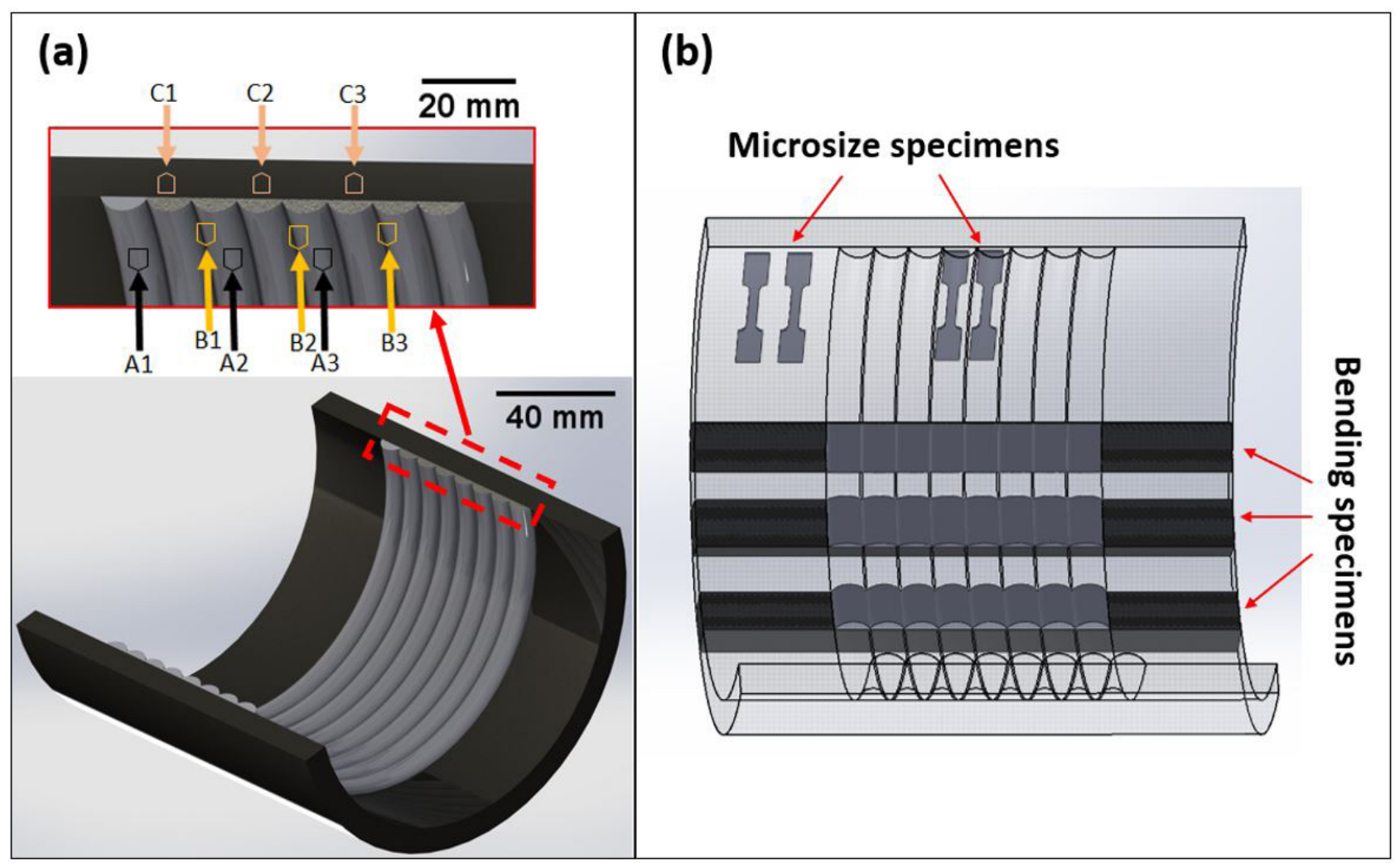

Figure 4. Locations for: (a) microhardness measurements; (b) microsize tensile test specimens, and bending test samples.

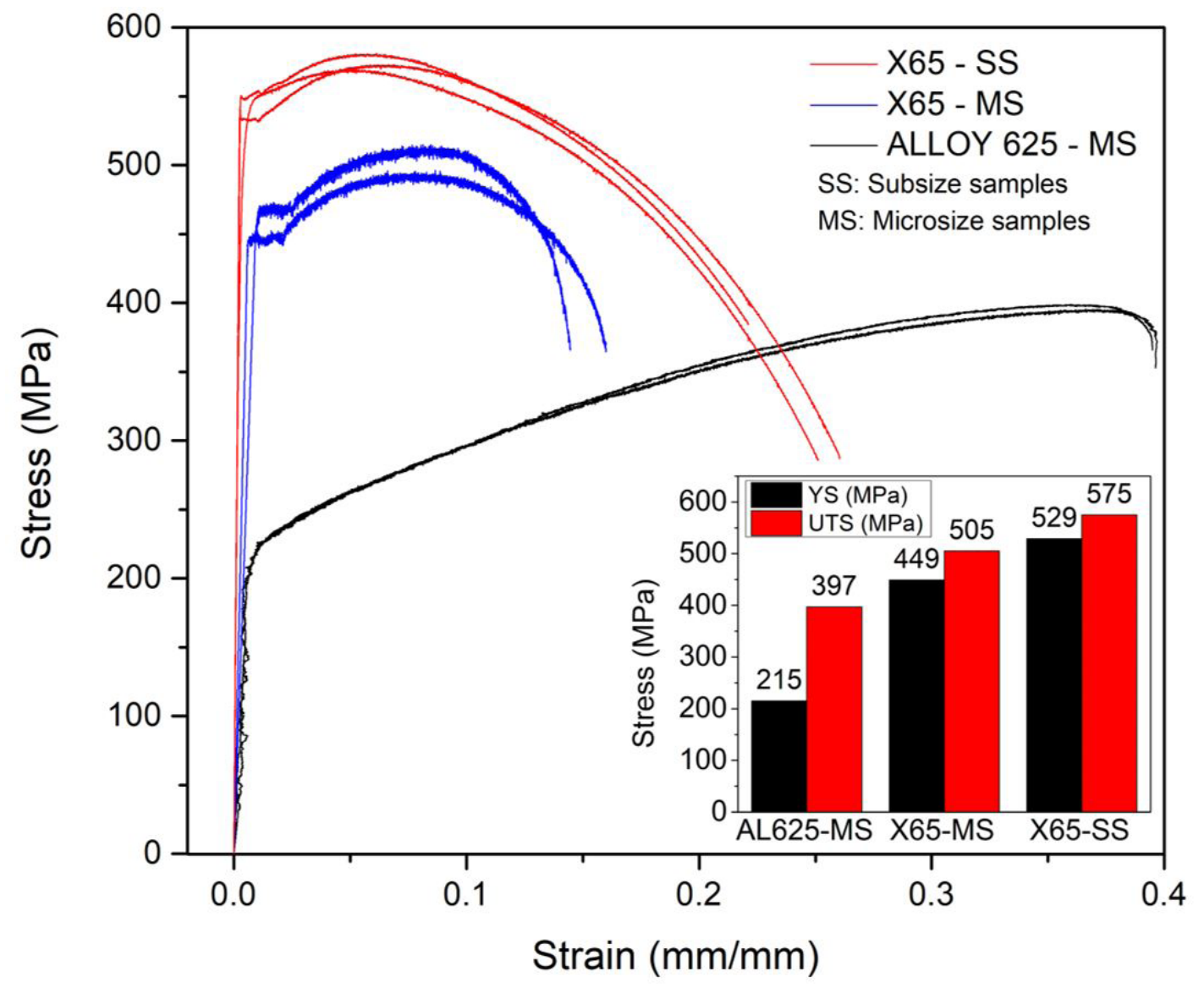

Figure 5. Mechanical properties of the materials. 
For microsize (MS) samples, the alloy 625 presented reduced mechanical properties compared to that of the API X65 steel. The diminished properties of the alloy 625 overlay might be related to the resulting microstructure from fusion welding. Thus, the alloy 625 microsize samples showed average YS and UTS of 215 and $397 \mathrm{MPa}$, respectively. Moreover, MS samples of the API X65 steel reached higher mechanical properties (YS and UTS).

The differences between SS and MS results of the API X65 steel are expected due to variations in the samples' dimensions (Figure 3). Therefore, MS samples considered a local and small part of the API X65 steel (close to its internal surface (Figure $4 b$ ), whilst the SS samples a greater area (related to the pipe wall thickness).

\subsection{Microhardness}

Table 2 presents the microhardness values of the regions analyzed (Figure 4a). The hardness values should be lower than $250 \mathrm{HV}$, as indicated in [24]. Therefore, none of the measurements exceeded these recommendations. Also, the API X65 steel reached higher microhardness than the alloy 625 . The same trend of increased mechanical properties was observed in tensile testing (Figure 5).

\subsection{Microstructural observation}

Figure 6 shows the microstructure of the alloy 625 cladding layer. As the weld metal was deposited by fusion welding, the dendritic feature is observed. As a consequence

Table 2. Microhardness results at different locations

\begin{tabular}{llll}
\hline \multicolumn{1}{c}{ Measurement location } & \#1 & \# 2 & \# 3 \\
\hline Alloy 625 deposit at the surface (A1, A2, and A3) & $175 \mathrm{HV}$ & $186 \mathrm{HV}$ & $182 \mathrm{HV}$ \\
Limit region between two weld beads (B1, B2, and B3) & $209 \mathrm{HV}$ & $184 \mathrm{HV}$ & $175 \mathrm{HV}$ \\
API 5L X65 steel (C1, C2, and C3) & $224 \mathrm{HV}$ & $223 \mathrm{HV}$ & $221 \mathrm{HV}$ \\
\hline
\end{tabular}
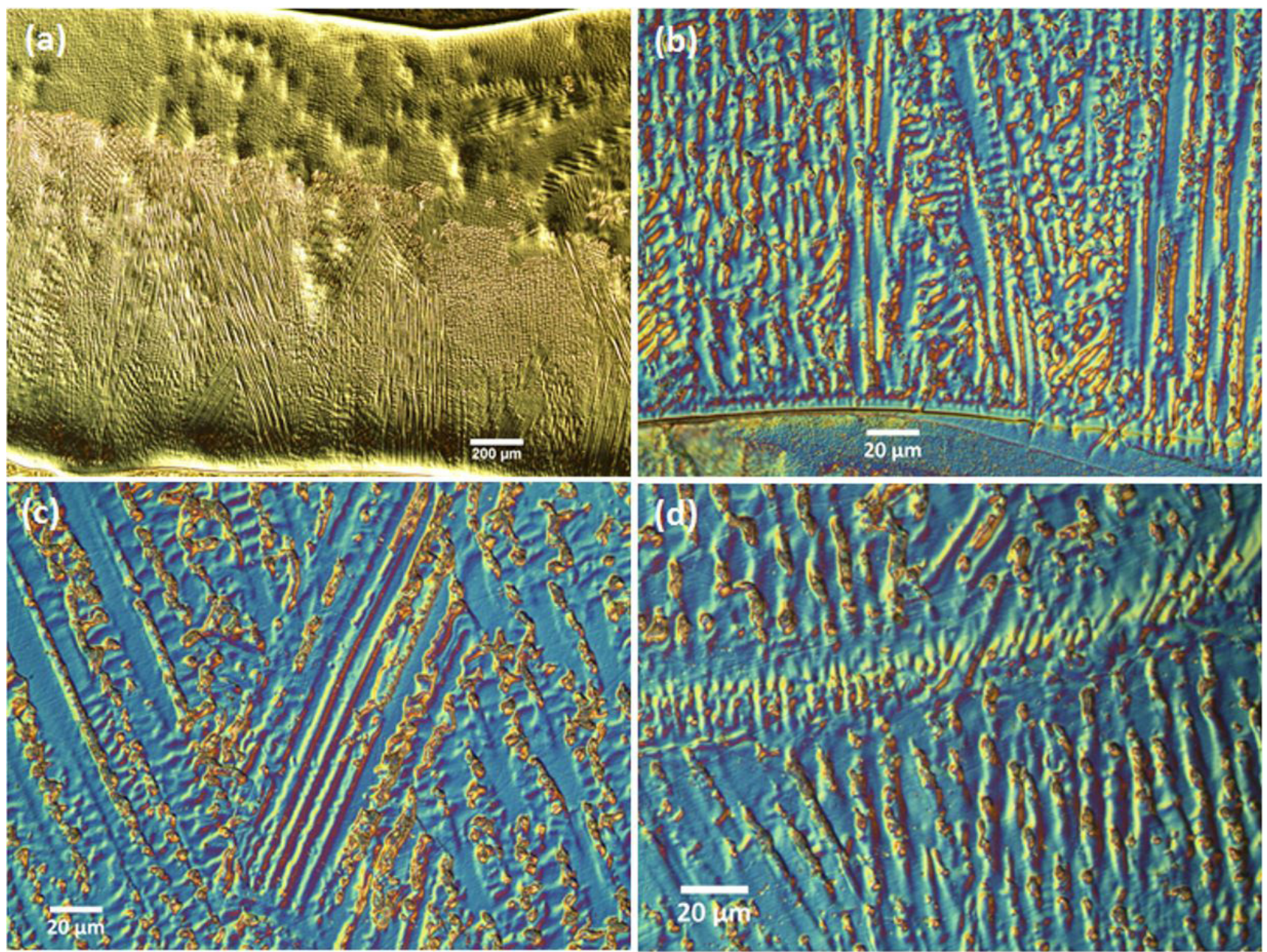

Figure 6. Dendritic structure of the alloy 625 cladding layer at distinct regions. 
of the temperatures reached during the welding overlay, associated with the helical shape that the metal is deposited, the reheat of the previous weld bead occurs. Thus, the alloy 625 microstructure can be modified by annealing the prior bead.

Microstructural features of the materials (API X65 and alloy 625) were also evaluated via SEM. Therefore, Figure 7 presents the API X65 steel microstructure. It can be noticed a microstructure based on ferrite, which may be a characteristic of HSLA steels. It can also be seen the grain boundaries and the ferrite in finer grains of varying sizes.

In Figure 8, at the surface of alloy 625, SEM images show the overlay microstructure at different magnifications.
Thus, in Figure 8b, carbides displaced into the dendritic arms can be observed.

Figure 9 displays the limit region between two weld beads. The microstructural transformations promoted by the reheating, which occurs during the overlay, can be seen. Therefore, the previous weld bead's fusion did not lead to defects (as the lack of fusion).

Figure 10 shows the SEM micrographs at the interface between the materials (API X65 and alloy 625). In this context, a grain growth near the interface is observed. Furthermore, the weld presented $8.2 \%$ of dilution (verified via Equation 1). The iron content estimated in the weld was $8.36 \%$ from the dilution data, which complies with the requirements of the API 6A standard [15].
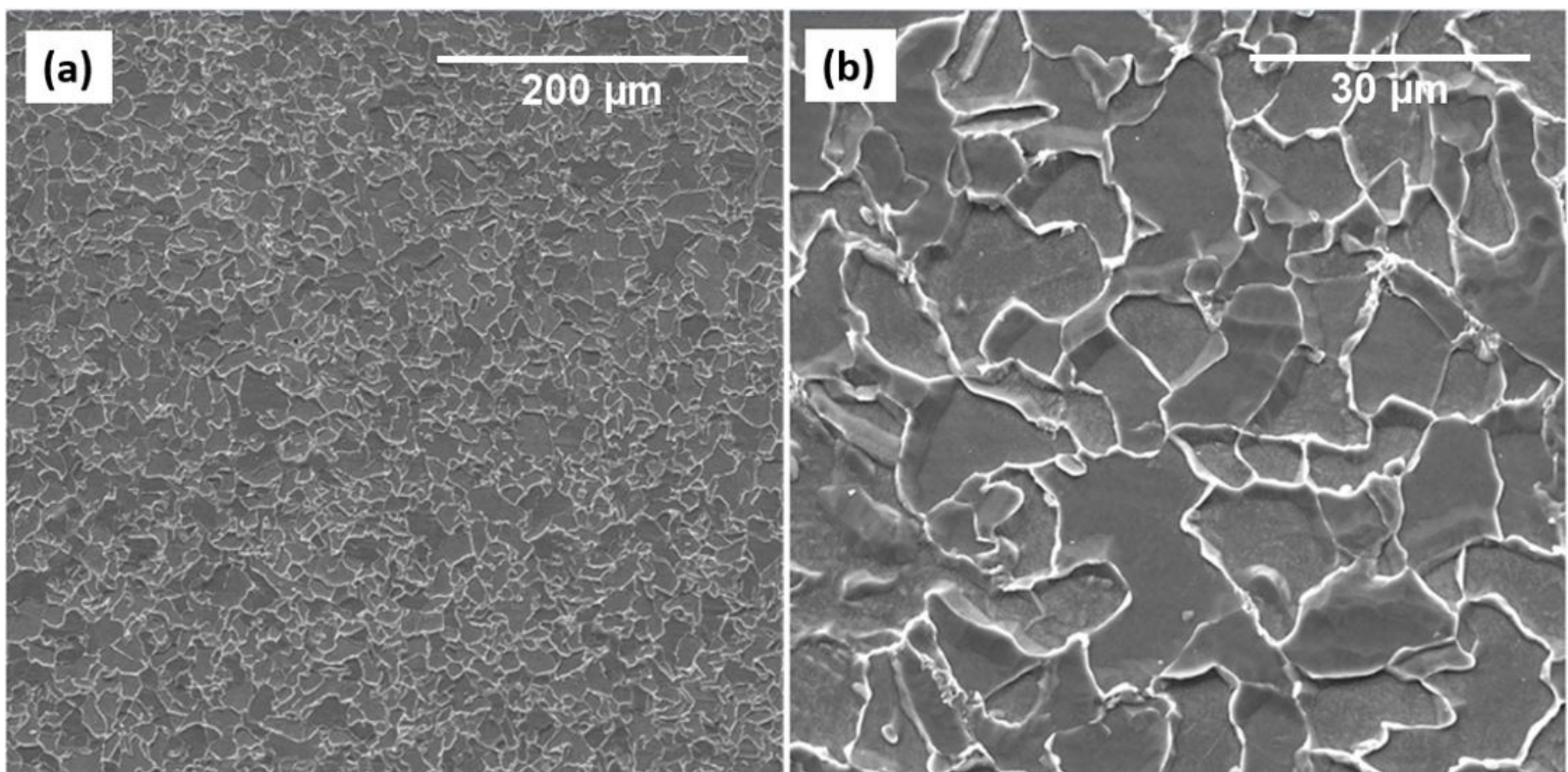

Figure 7. SEM micrographs of the X65 steel. Magnification: (a) 1000X; and (b) 6000X.

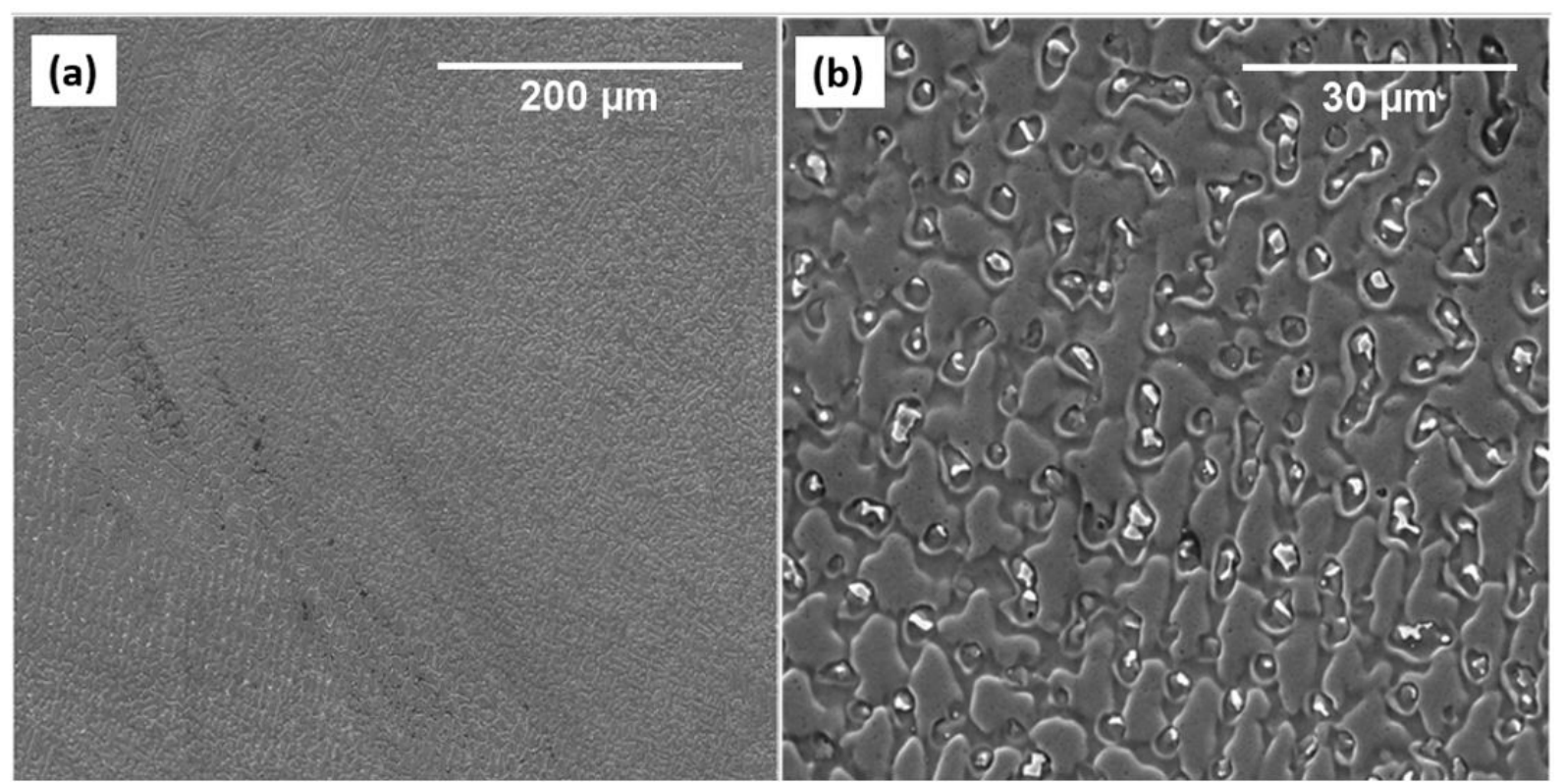

Figure 8. SEM micrographs of the alloy 625 layer. Magnification: (a) 1000X; and (b) 6000X. 


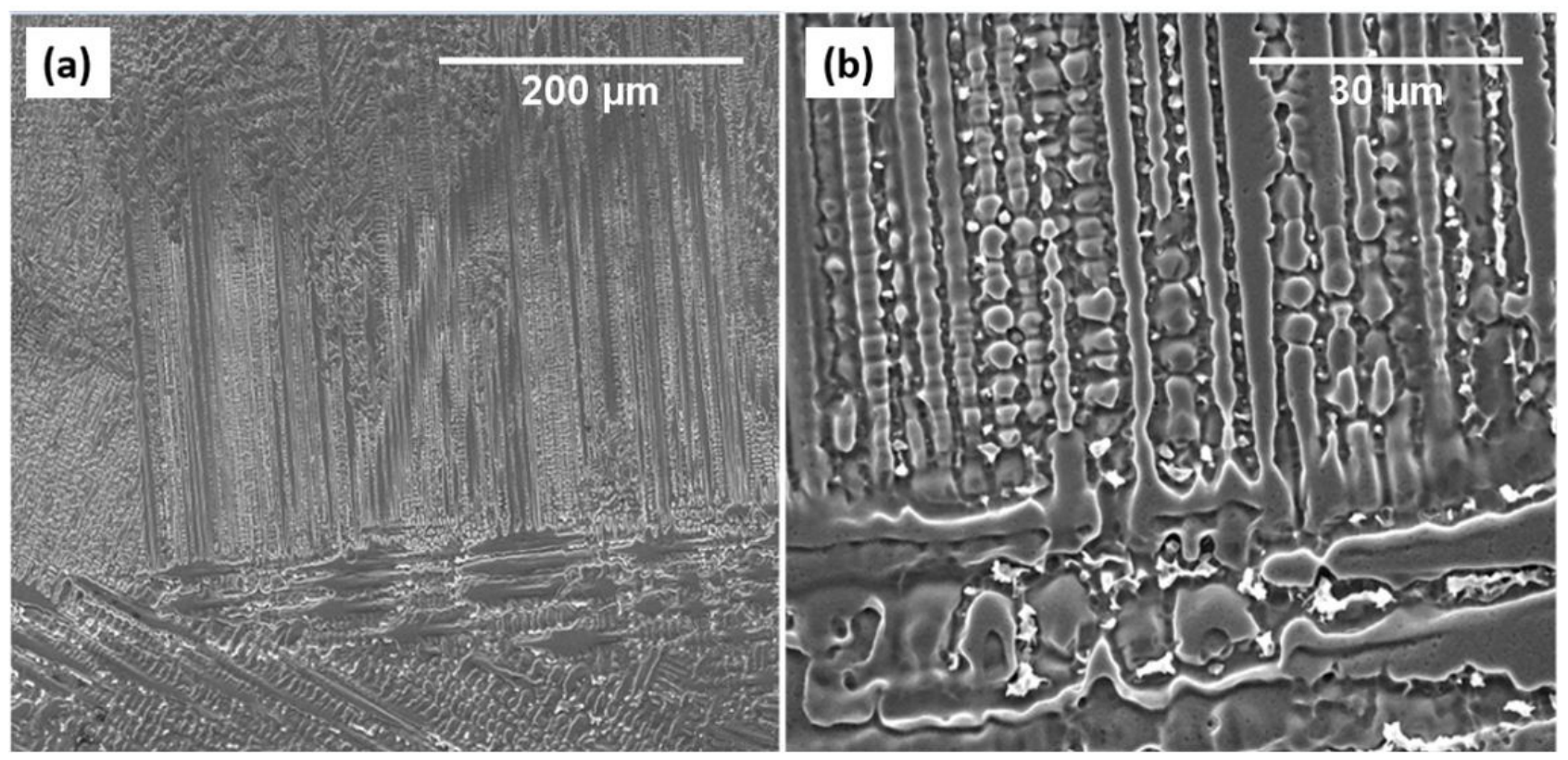

Figure 9. SEM micrographs of the limit region between two weld beads: (a) 1000X; and (b) 6000X.
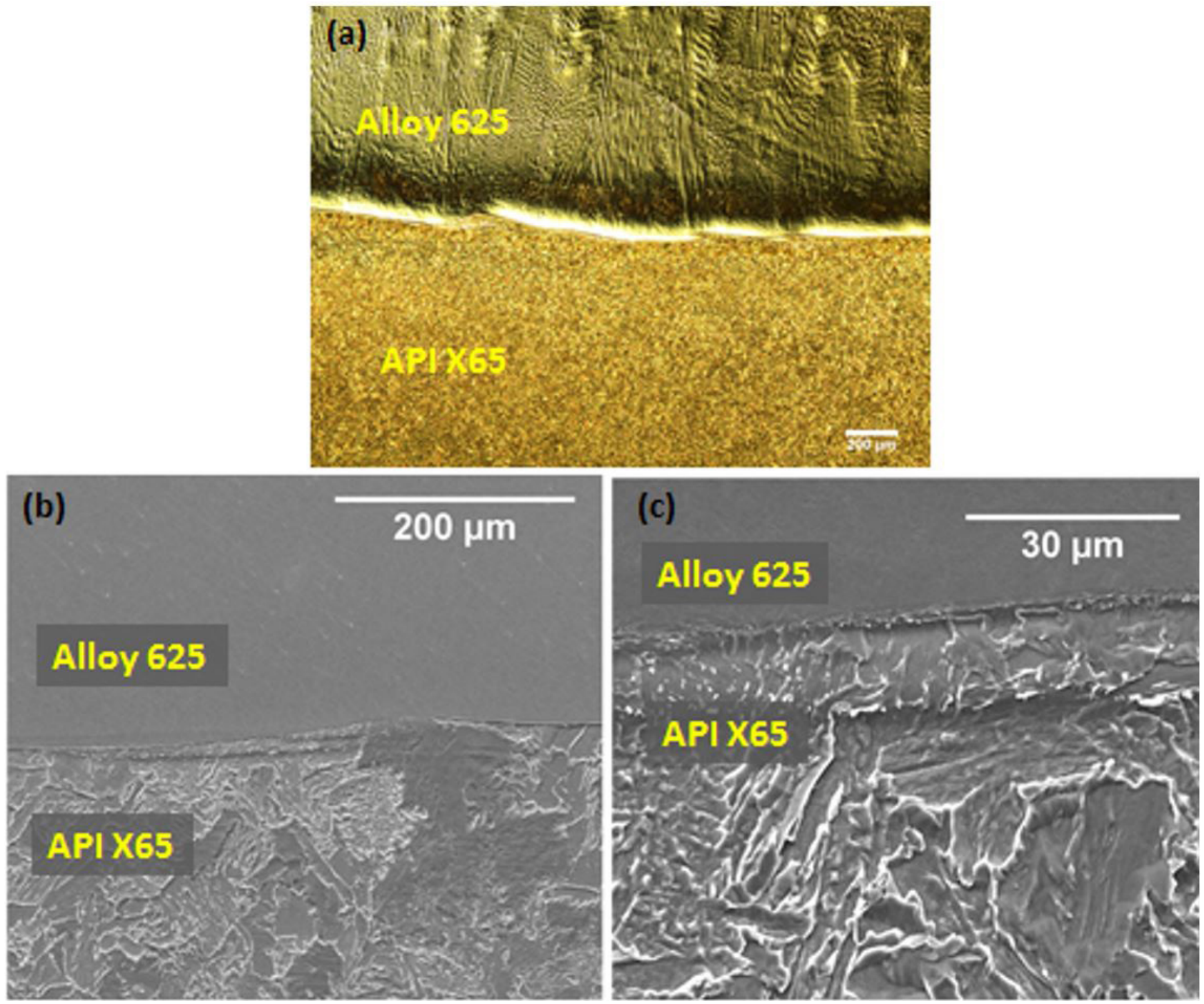

Figure 10. Micrographs at the interface. (a) Optical microscopy; SEM images: (b) 1000X; and (c) 6000X. 


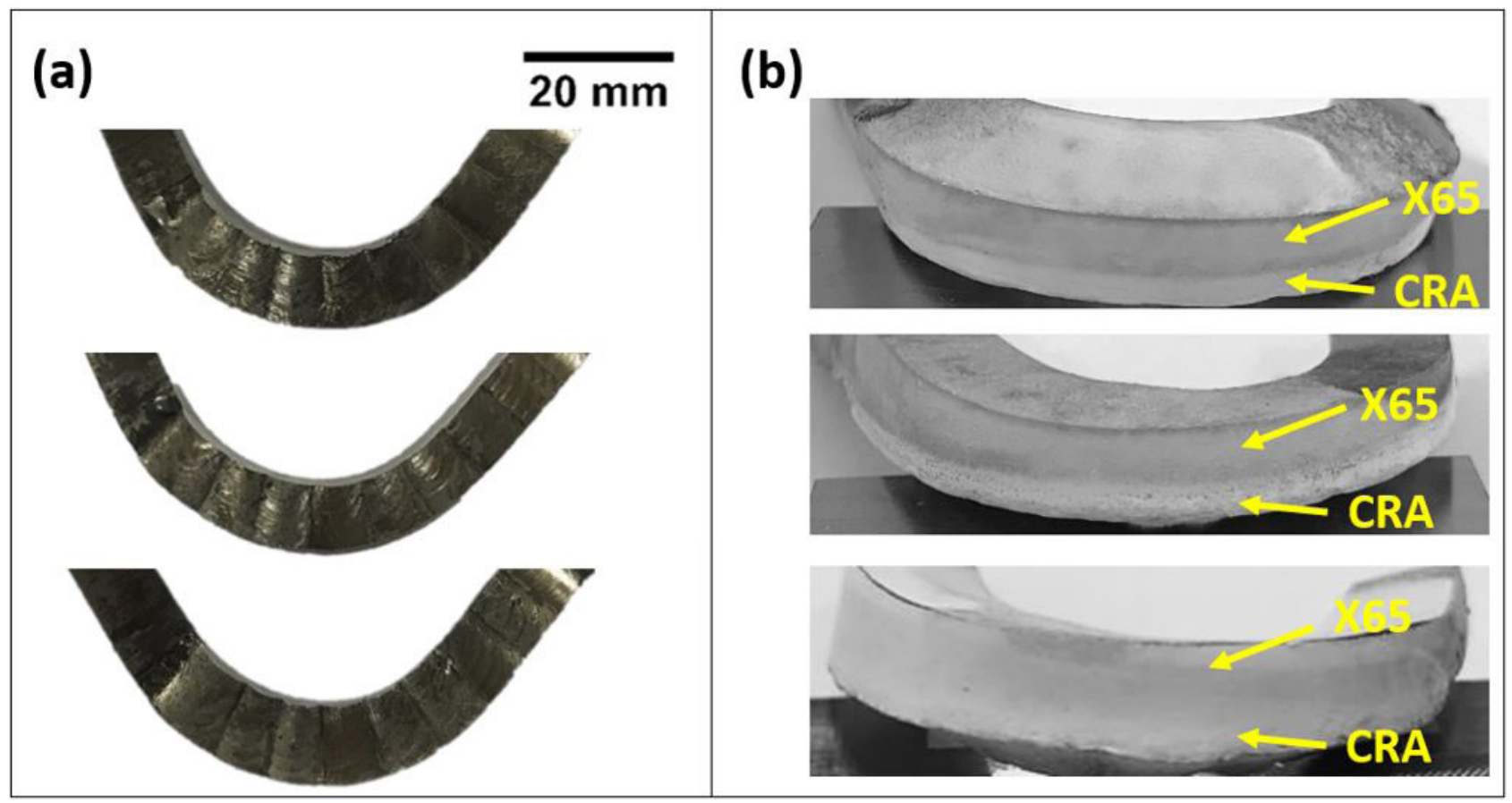

Figure 11. (a) Samples bent, (b) Samples after the dye penetrant test.

\subsection{Bending tests}

Figure 11a shows the samples bent, while Figure 11b displays the dye penetrant test applied to them. The LPT results were very similar for all three samples. Thus, the non-destructive test inspection showed the samples bent (Figure $11 \mathrm{~b}$ ), which are free of cracks or defects at the interface.

\section{Conclusions}

An API 5L X65 carbon steel pipe cladded with alloy 625 was evaluated in this work. Therefore, the following conclusions can be drawn: i) A cladding layer of alloy 625 was successfully deposited in an API X65 steel substrate using TIG hotwire process;

ii) In microsize tensile tests, it was observed that the alloy 625 has lower mechanical properties than the API X65 steel. In the same way, the microhardness values of the alloy 625 overlay were lower than the API X65 steel. Thus, the API X65 PSL2 steel presented enhanced mechanical properties;

iii) Bending tests showed no defects or cracks at the interface. Furthermore, the dye penetrant test proved a suitable overlay quality.

\section{References}

1 Obeid O, Alfano G, Bahai H. Thermo-mechanical analysis of a single-pass weld overlay and girth welding in lined pipe. Journal of Materials Engineering and Performance. 2017;26:3861-3876.

2 Macdonald KA, Cheaitani M. Engineering critical assessment in the complex girth welds of clad and lines pipe materials. In: Proceedings of the 8th International Pipeline Conference; Calgary, Alberta, Canada; 2010. ASME. IPC2010-31627.

3 Moninea VI, Gonzaga RS, Farias FWC, Passos EKD, Payão JC Fo. Study of mechanical behavior and X-ray elastic constants of nickel alloy weld overlay. Materials Research. 2019;22(4):e20180719.

4 Smith L. Engineering with clad steel. 2nd ed. Canada: Nickel Institute; 2012.

5 Amudha A, Shashikala HD, Nagaraja HS. Corrosion protection of low-cost carbon steel with SS-309Mo and Inconel-625 bimetallic weld overlay. Materials Research Express. 2019;6(4):046523.

6 Kim JS, Park YI, Lee HW. Effects of heat input on the pitting resistance of inconel 625 welds by overlay welding. Metals and Materials International. 2015;21:350-355.

7 Lemos GVB, Hanke S, Dos Santos JF, Bergmann L, Reguly A, Strohaecker TR. Progress in friction stir welding of Ni alloys. Science and Technology of Welding and Joining. 2017;22(8):643-657. 
8 Bunaziv I, Olden V, Akselsen OM. Metallurgical aspects in the welding of clad pipelines-A global outlook. Applied Sciences (Basel, Switzerland). 2019;9(15):3118.

9 Baiotto R, Knight-Gregson B, Nageswaran C, Clarke T. Coherence weighting applied to FMC/TFM data from austenitic CRA clad lined pipes. Journal of Nondestructive Evaluation. 2018;37:49.

10 Johnston C, Nageswaran C, London T. Investigations into the fatigue strength of CRA lined pipe. Offshore Technology Conference. Houston; Texas, USA. OTC; 2016.

11 Longlong G, Hualin Z, Shaohu L, Yueqin L, Xiaodong X, Chunyu F. Formation quality optimization and corrosion performance of Inconel 625 weld overlay using hot wire pulsed TIG. Rare Metal Materials and Engineering. 2016;45(9):2219-2226.

12 Olivares E, Díaz V. Estudo do processo TIG Hot-Wire com material de adição AISI-316L analisando o efeito do sopro magnético do arco sobre a diluição do cordão de solda. Soldagem e Inspeção. 2016;21(3):330-341.

13 Alvarães CP, Madalena FCA, Souza LFG, Jorge JCF, Araújo LS, Mendes MC. Performance of the INCONEL 625 alloy weld overlay obtained by FCAW process. Revista Matéria. 2019;24(1):1-12.

14 DNV GD. DNVGL-ST-F101: submarine pipeline systems. Noruega: DNV GD; 2017.

15 American Petroleum Institute. API 6A - Specification for Wellhead and Christmas Tree Equipment. Washington: API; 2005.

16 Song K, Wang Z, Hu S, Zhang S, Liang E. Welding current influences on Inconel 625/X65 cladding interface. Materials and Manufacturing Processes. 2018;33:770-777.

17 Rajkumar V, Arjunan TV, Kannan R. Metallurgical and mechanical investigations of Inconel 625 overlay welds produced by GMAW hardfacing process on AISI 347 pipes. Materials Research Express. 2019;6:076534.

18 Chong TVS, Kumar SB, Lai MO, Loh WL. Effects of elevated temperatures on the mechanical properties of nickelbased alloy clad pipelines girth welds. Engineering Fracture Mechanics. 2016;152:174-192.

19 Elango P, Balaguru S. Welding parameters for inconel 625 overlay on carbon steel using GMAW. Indian Journal of Science and Technology. 2015;8(31):1-5.

20 Lessa CRL, Landell RM, Bergmann L, Santos JF, Kwietniewski CEF, Reguly A, et al. Two-pass friction stir welding of cladded API X65. Procedia Manufacturing. 2020;47:1010-1015. http://dx.doi.org/10.1016/j.promfg.2020.04.311.

21 Rogalski G, Fydrych D, Łabanowski J. Underwater wet repair welding of API 5L X65M pipeline steel. Polish Maritime Research. 2017;24(Supplement 1):188-194.

22 Tahaei A, Vazquez FG, Merlin M. Metallurgical characterization of a weld bead coating applied by the PTA process on the D2 tool steel. Soldagem e Inspeção. 2016;21(2):209-219.

23 ASTM International. ASTM E8/E8M: Standard Test Methods for Tension Testing of Metallic Materials. West Conshohocken: ASTM International; 2013.

24 American Petroleum Institute. API 5L - Specification for Line Pipe. Washington: API; 2004.

Received: 18 Aug. 2020

Accepted: 21 Oct. 2020 